\title{
Lymphoid tissue fibrosis is associated with impaired vaccine responses
}

\author{
Cissy Kityo, ${ }^{1}$ Krystelle Nganou Makamdop, ${ }^{2}$ Meghan Rothenberger, ${ }^{3}$ Jeffrey G. Chipman, ${ }^{3}$ Torfi Hoskuldsson, ${ }^{3}$ Gregory J. Beilman, ${ }^{3}$ \\ Bartosz Grzywacz, ${ }^{3}$ Peter Mugyenyi, ${ }^{1}$ Francis Ssali, ${ }^{1}$ Rama S. Akondy, ${ }^{4}$ Jodi Anderson, ${ }^{3}$ Thomas E. Schmidt, ${ }^{3}$ Thomas Reimann, ${ }^{3}$ \\ Samuel P. Callisto, ${ }^{3}$ Jordan Schoephoerster, ${ }^{3}$ Jared Schuster, ${ }^{3}$ Proscovia Muloma, ${ }^{1}$ Patrick Ssengendo, ${ }^{1}$ Eirini Moysi, ${ }^{2}$ \\ Constantinos Petrovas, ${ }^{2}$ Ray Lanciotti, ${ }^{5}$ Lin Zhang, ${ }^{3}$ Maria T. Arévalo, ${ }^{6}$ Benigno Rodriguez, ${ }^{7}$ Ted M. Ross, ${ }^{6}$ Lydie Trautmann, ${ }^{8,9}$ \\ Rafick-Pierre Sekaly, ${ }^{7}$ Michael M. Lederman, ${ }^{7}$ Richard A. Koup, ${ }^{10}$ Rafi Ahmed, ${ }^{4}$ Cavan Reilly, ${ }^{3}$ Daniel C. Douek, ${ }^{2}$ \\ and Timothy W. Schacker ${ }^{3}$
}

Joint Clinical Research Center, Kampala, Uganda. ${ }^{2}$ Human Immunology Section, Vaccine Research Center, National Institute of Allergy and Infectious Diseases, National Institutes of Health, Bethesda, Maryland, USA. ${ }^{3}$ University of Minnesota, Minneapolis, Minnesota, USA. ${ }^{4}$ Emory Vaccine Center, and Department of Microbiology and Immunology, Emory University, Atlanta, Georgia, USA. ${ }^{5}$ Centers for Disease Control, Atlanta, Georgia, USA. ${ }^{6}$ Center for Vaccines and Immunology and Department of Infectious Diseases, University of Georgia, Athens, Georgia, USA. 'ase Western Reserve University, Cleveland, Ohio, USA. ${ }^{8}$ U.S. Military HIV Research Program, Walter Reed Army Institute of Research, Silver Spring, Maryland, USA. ${ }^{9} \mathrm{Henry}$ M. Jackson Foundation for the Advancement of Military Medicine, Bethesda, Maryland, USA. ${ }^{10}$ Immunology Laboratory, Vaccine Research Center, National Institute of Allergy and Infectious Diseases, National Institutes of Health, Bethesda, Maryland, USA.

\begin{abstract}
Vaccine responses vary by geographic location. We have previously described how HIV-associated inflammation leads to fibrosis of secondary lymph nodes (LNs) and T cell depletion. We hypothesized that other infections may cause LN inflammation and fibrosis, in a process similar to that seen in HIV infection, which may lead to T cell depletion and affect vaccine responses. We studied LNs of individuals from Kampala, Uganda, before and after yellow fever vaccination (YFV) and found fibrosis in LNs that was similar to that seen in HIV infection. We found blunted antibody responses to YFV that correlated to the amount of LN fibrosis and loss of T cells, including T follicular helper cells. These data suggest that LN fibrosis is not limited to HIV infection and may be associated with impaired immunologic responses to vaccines. This may have an impact on vaccine development, especially for infectious diseases prevalent in the developing world.
\end{abstract}

\section{Introduction}

Vaccine responses are known to vary geographically. Bacillus Calmette-Guerin (BCG) for tuberculosis (TB) is perhaps the best known example of a vaccine for which efficacy rates vary according to geography, with better responses occurring in northern latitudes (1). Rotavirus vaccine is another example where sustained, neutralizing antibody titers are achieved after a single dose in the U.S. and Europe, but in developing countries protection is absent or short-lived even after multiple doses (2-4). Polio and cholera are also associated with poor antibody responses in developing countries (5-11) and it was recently shown that yellow fever vaccine (YFV) was associated with low levels of neutralizing antibodies in Uganda compared with Switzerland, and that heightened immune activation (IA) in Ugandans was an important factor limiting vaccine responses (12). This is important, as chronic IA may lead to T cell anergy (13), which would limit adaptive immune responses.

\section{Related Commentary: p. 2743}

Authorship note: CK and KNM contributed equally to this work. Conflict of interest: The authors have declared that no conflict of interest exists. Submitted: September 26, 2017; Accepted: April 10, 2018. Reference information: J Clin Invest. 2018;128(7):2763-2773. https://doi.org/10.1172/JCI97377.
Reasons for chronic IA and geographic differences in vaccine response are unknown but one possible explanation is that local environmental conditions or endemic infections somehow affect immune function. There are several studies documenting poor induction of adaptive immunity in the setting of a chronic infection, especially with helminthic infections (14-17). The mechanism is unknown but it is likely related to altered cytokine responses to infection that affect $\mathrm{T}$ cell proliferation and antibody formation (15). HIV is an infection that is associated with decreased immune function because of loss of $\mathrm{CD} 4^{+} \mathrm{T}$ cells and chronic IA (even during fully suppressive antiretroviral therapy) (18-20). There are multiple mechanisms that contribute to CD $4^{+}$ T cell loss in HIV infection. Lymphatic tissue (LT) fibrosis from HIV replication is a significant mechanism caused by an inflammatory reaction that leads to collagen formation in the parafollicular T cell zone (TZ) (21). This fibrosis replaces the fibroblastic reticular cell network (FRCn), a structure that is vital to normal immune function. The FRCn is a scaffold-like structure with several functions important to the development of mature immune responses. $\mathrm{T}$ cells and antigen presenting cells (APCs) migrate across these fibers so that antigen-specific $\mathrm{T}$ cells can interact with their cognate antigen on APCs $(22,23)$. The FRCn fibers are also hollow conduits through which soluble antigen may flow to gain access to the $\mathrm{TZ}(24,25)$ and, importantly, the fibers also produce the $\mathrm{T}$ cell homeostatic cytokine IL-7. Loss of 
Table 1. Summary of demographic data

\begin{tabular}{|c|c|c|c|c|}
\hline & \multirow{2}{*}{$\begin{array}{l}\text { HIV }^{+} \\
\text {U.S. }\end{array}$} & \multicolumn{3}{|c|}{ HIV $^{-}$} \\
\hline & & Uganda & Minnesota & Georgia \\
\hline $\mathrm{N}$ (percent) & 24 (31.6) & 30 (39.5) & $12(15.8)$ & $10(13.2)$ \\
\hline Female: number (percent) & $1(4.2)$ & $16(53.3)$ & $3(25)$ & $4(40)$ \\
\hline Age: median (quartiles) & $37.5(33.6,44.9)$ & $31.3(20.8,35.1)$ & $42.2(38.9,48.9)$ & $39(38,41.8)$ \\
\hline $\mathrm{CD}^{+} \mathrm{T}$ cell count: median (quartiles) & $348(212.8,504)$ & $874.5(699.8,1103.8)$ & $953(752.8,1162.2)$ & $\mathrm{n} / \mathrm{a}$ \\
\hline
\end{tabular}

n/a, not applicable.

the FRCn significantly reduces IL-7 levels in the TZ $(21,26,27)$, which leads to depletion of $\mathrm{T}$ cells, making this an important mechanism for $\mathrm{CD}^{+} \mathrm{T}$ cell loss in $\operatorname{HIV}$ infection $(28,29)$. It is unknown if this process of $\mathrm{LN}$ fibrosis leading to lower $\mathrm{CD} 4^{+} \mathrm{T}$ cell counts occurs with other infections; however, in large population-based studies of $\mathrm{HIV}^{-}$people in East Africa, the average $\mathrm{CD}^{+} \mathrm{T}$ cell count is significantly lower than in Northern European populations (30). For example, in Uganda, the mean CD $4^{+}$ $\mathrm{T}$ cell count is 754 cells $/ \mathrm{mm}^{3}$ for males and 894 cells $/ \mathrm{mm}^{3}$ for females (30), and in Ethiopia the mean $\mathrm{CD}^{+} \mathrm{T}$ cell count, overall, is 667 cells $/ \mathrm{mm}^{3}$ but in Denmark it is 1,067 cells $/ \mathrm{mm}^{3}(31)$. There are similar studies from other parts of the world that show the same trend of higher $\mathrm{CD} 4^{+} \mathrm{T}$ cell counts in countries further north than Uganda or in more developed countries (32-34).
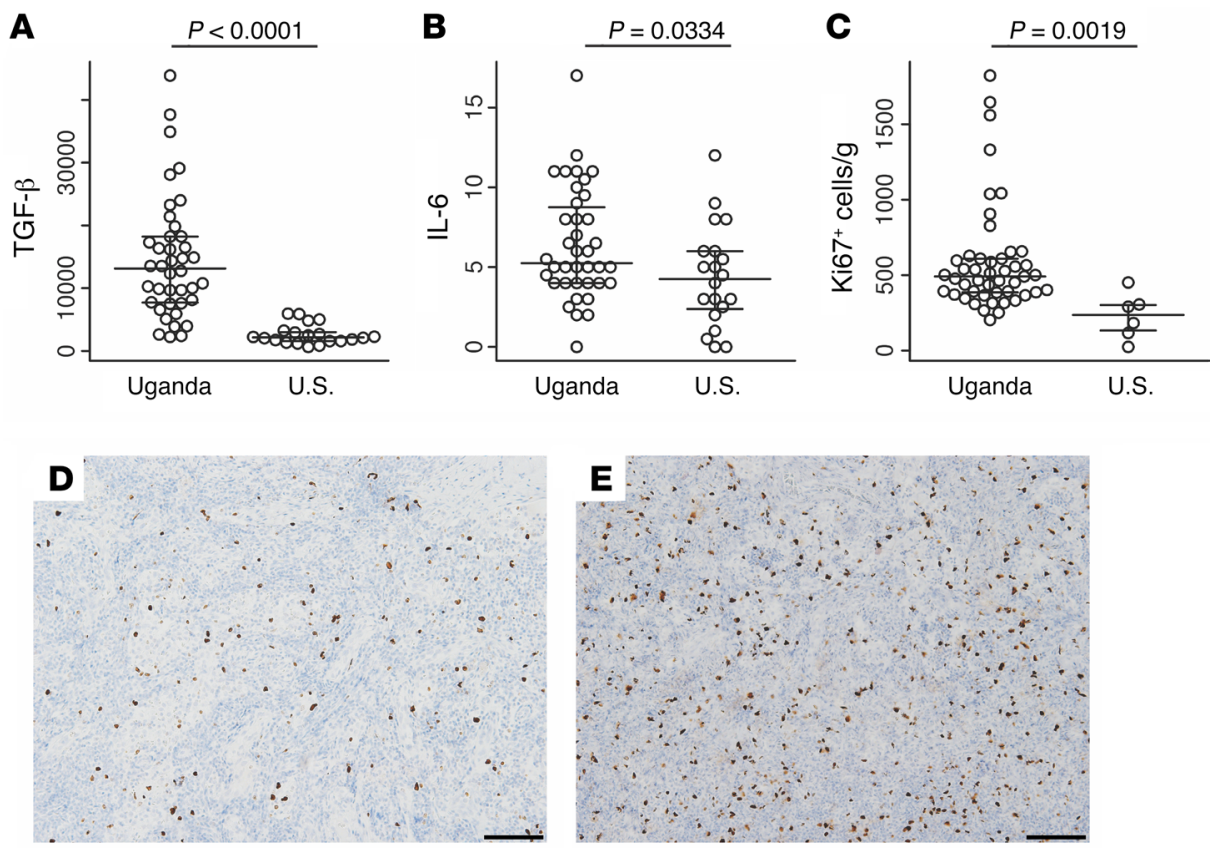

Figure 1. Increased immune activation in HIV- Ugandans. Prevaccination plasma samples demonstrated elevated levels of TCF- $\beta$ (A) and IL-6 (B) in a group from Uganda compared with a group from the U.S. LN sections stained for Ki67 also demonstrated increased immune activation when compared with LN tissues obtained from people in the U.S. (C). Representative sections of LN stained with Ki67 antibodies from an HIV negative person in Minnesota (D) and an HIV negative Ugandan (E) are shown. Scale bars indicate $100 \mu \mathrm{m}$ and magnification is $\times 10$.
We reasoned that small $\mathrm{CD}^{+} \mathrm{T}$ cell populations in equatorial locales may be caused by a process similar to the one we described above for HIV. Constant exposure to endemic infections may lead to chronic IA that could cause TZ fibrosis and damage to the FRCn. This, in turn, would lead to smaller populations of $\mathrm{CD} 4^{+}$and $\mathrm{CD} 8^{+}$ $\mathrm{T}$ cells and all of their subpopulations. This could have an impact on B cell function for several reasons. T follicular helper (Tfh) cells may become depleted as part of the general loss of $\mathrm{CD} 4^{+} \mathrm{T}$ cells from LN fibrosis. Also, structural damage to the FRCn could directly impact a humoral response, as it has recently been shown that the FRCn is critical to follicle formation and normal B cell function (35) in that loss of the FRCn leads to decreased production of B cell activating factor (also made by the FRCn), leading to reduced numbers of B cells and impaired response to vaccination (36).

We examined this hypothesis by studying the structure of LNs from HIV people in Uganda and determining the degree to which LN architecture was disrupted by TZ fibrosis and $\mathrm{T}$ cells were depleted. We then vaccinated individuals with YFV and studied immune responses by collecting another LN sample 10 days after vaccination and following neutralizing antibody titers for 14 months.

\section{Results}

Protocol description. We recruited 3 groups of individuals to address our hypothesis. Group 1 included $30 \mathrm{HIV}^{-}$Ugandans who were assessed for baseline measures of inflammatory cytokines in blood and measures of IA in blood and LNs. A subset of 20 of this group was then given YFV with follow-up sampling of peripheral blood (PB) and LNs 10-14 days after vaccination, a time point when germinal center (GC) formation is at its peak $(37,38)$. The subset was followed for 14 months to obtain serial blood samples to measure yellow fever antibody titers in PB. Group 2 consisted of $10 \mathrm{HIV}^{-}$individuals from Minnesota, USA, who had been recruited 
Table 2. Summary of cytokine data in terms of model-based estimates of mean levels

\begin{tabular}{|c|c|c|c|c|c|c|c|c|}
\hline & \multicolumn{4}{|c|}{ Means } & \multicolumn{4}{|c|}{$P$} \\
\hline & Uganda & Uganda & U.S. & U.S. & Uganda & U.S. & Between countries & Between countries \\
\hline & Day 0 & Week 2 & Day 0 & Week 2 & Day 0-Week 2 & Day 0-Week 2 & Day 0 & Week 2 \\
\hline TCF- $\beta$ & $17,768.7$ & $11,480.8$ & $2,464.6$ & 2,763 & 0.002 & 0.608 & $<0.001$ & $<0.001$ \\
\hline IL-13 & 17.4 & 22.7 & 10.2 & 8.5 & 0.107 & 0.013 & 0.083 & 0.002 \\
\hline IL-10 & 4.1 & 9 & 3.8 & 5.2 & $<0.001$ & 0.063 & 0.646 & 0.179 \\
\hline IL-17A & 33.6 & 51.1 & 35 & 37.3 & 0.004 & 0.31 & 0.889 & 0.053 \\
\hline IL-4 & 3.2 & 7 & 0.8 & 0.7 & 0.051 & 0.701 & 0.004 & $<0.001$ \\
\hline IL-6 & 1.4 & 1.6 & 0.9 & 1 & 0.1 & 0.646 & 0.033 & 0.001 \\
\hline IL-21 & 1.5 & 3.3 & $<0.001$ & $<0.001$ & 0.006 & 1.0 & 0.001 & $<0.001$ \\
\hline IL-22 & 0.5 & 3.2 & $<0.001$ & $<0.001$ & 0.022 & 1.0 & 0.362 & 0.008 \\
\hline IL-23 & 0.1 & 2.3 & 0.6 & 0.6 & $<0.001$ & 0.781 & 0.588 & 0.012 \\
\hline IL-1 $\beta$ & 1.2 & 3.2 & 1.6 & 0.6 & 0.005 & 0.351 & 0.69 & 0.004 \\
\hline TNF & 63.6 & 48.3 & 65.7 & 56.9 & 0.065 & 0.81 & 0.811 & 0.324 \\
\hline CXCL13 & 30.1 & 37.9 & 22.7 & 24.5 & 0.006 & 0.489 & 0.451 & 0.085 \\
\hline IP-10 & 265 & 453.7 & 208.8 & 223.8 & $<0.001$ & 0.107 & 0.062 & $<0.001$ \\
\hline MIP-1 $\beta$ & 57.6 & 49.3 & 36.8 & 35.4 & 0.065 & 0.137 & 0.01 & 0.077 \\
\hline
\end{tabular}

Models were controlled for age, sexual phenotype, and measurements using the same subject over time. TGF- $\beta$ and CXCL13 results are pg/ml and the remaining measures are mean fluorescence intensity (MFI).

into another protocol (A Protocol to Study the Kinetics of HIV Replication and Cellular Mechanisms Supporting Viral Replication in Lymphatic Tissue and Study of Dynamic Changes in Lymphocyte Populations and Lymphatic Architecture Before and During HIV-1 Therapy) in which LN biopsies and PB samples were obtained; these samples were used as comparators to the Ugandan tissues. Group 3 consisted of $10 \mathrm{HIV}^{-}$participants in a study (Yellow Fever Vaccine and Immune Globulin Study; NCTO0254826) at Emory University in Atlanta, GA (39), who received YFV with PB collected before vaccination and again 10-14 days later (but no LNs were obtained), providing a group in the U.S. for comparison of immunologic and inflammatory responses elicited by YFV. Finally, LN measures of fibrosis and CD4 ${ }^{+}$ T cells from $\mathrm{HIV}^{+}$people from Minnesota, USA, were included in the analysis as positive controls for LN fibrosis (27). Demographic data for all participants are shown in Table 1 .

$H I V$ Ugandans have elevated levels of IA. We first examined how plasma measures of inflammatory cytokines (IL-1 $\beta$, IL-4, IL-6, IL-10, IL-17A, IL-21, IL-22, IL-23, IL-13, MIP-1 $\beta$, TNF, TGF- $\beta$, IP-10) varied with geographic location and time. We were particularly interested in TGF- $\beta$ as it is the proinflammatory cytokine we have previously shown is associated with formation of LN TZ fibrosis (40). Before YFV administration, we observed significantly higher levels of TGF- $\beta$, IL-6, IL-4, IL-21, and MIP-1 $\beta$ in Uganda than in the U.S. $(P<0.001, P=0.03, P=0.004, P=0.001$, and $P=0.01$, respectively), as seen in Figure 1, A and B, and Table 2; however, no other statistically significant differences were detected in measured plasma cytokines. We also used IHC to stain for Ki67 ${ }^{+}$cells in LN. Ki67 ${ }^{+}$ is a common histologic marker of IA that marks cells that are in or have recently entered the cell cycle. Using quantitative image analysis (QIA) we found that Ugandans had significantly more frequent expression of $\mathrm{Ki}^{+} 7^{+}$cells $(P=0.0019$, Figure $1, \mathrm{C}-\mathrm{E})$ than individuals from the U.S. groups. These measures in plasma and tissue demonstrated that $\mathrm{HIV}^{-}$Ugandans have increased IA, especially in LT.
Increased collagen, decreased FRCn, and decreased $C D 4^{+} T$ cells in LNs from HIV Ugandans. We used trichrome staining and QIA to determine the amount of collagen in the TZ in Group 1. The mean area of the $\mathrm{TZ}$ with collagen in a subset of 20 of 30 participants in this group was $12.4 \%$ (SD 3.4\%) whereas in Group 2 it was $4.3 \%$ (SD 2.9\%). We next examined how the area of the TZ with collagen varied with geographic location and HIV status by comparing these data with data from a previously published study of TZ fibrosis in a group of $\mathrm{HIV}^{+}$subjects in Minnesota, USA (27), where the mean amount of TZ fibrosis was $12.9 \%$ (SD 7.4\%). The regression analysis after log-transformation of the percentage of $\mathrm{TZ}$ area showed a significantly increased amount of collagen in the TZ in Group 1 compared with Group $2(P<0.0001)$. While the amount of collagen in the $\mathrm{TZ}$ from $\mathrm{HIV}^{+}$people in Minnesota, USA, is increased over Group $1(P<0.0001)$, this comparison illustrates how the amount of TZ collagen in $\mathrm{HIV}^{-}$Ugandans is similar to that of $\mathrm{HIV}^{+}$people in Minnesota, USA (Figure 2, A-C). We also used QIA to measure the size of the $\mathrm{LN} \mathrm{CD} 4^{+} \mathrm{T}$ cell population in Group 1 for comparison to the measure of $\mathrm{TZ}$ collagen, as we have previously shown a significant and inverse correlation between them (21). The mean area of the $\mathrm{TZ}$ that contained $\mathrm{CD} 4^{+} \mathrm{T}$ cells was $28.2 \%$ (range $15.23 \%-$ $43.7 \%)$. We found an expected significant inverse correlation between TZ collagen and TZ CD4 ${ }^{+} \mathrm{T}$ cells $(P=0.0322)$; as collagen increases in the $\mathrm{TZ}$, the $\mathrm{CD} 4^{+} \mathrm{T}$ cell population becomes depleted (Figure 2D). There was no difference in the amount of TZ collagen between the sample obtained just prior to vaccination and the other LN sample obtained 2 weeks after vaccination. We next looked for evidence of increased numbers of $\mathrm{T}$ regulatory cells because of the elevated levels of TGF- $\beta$ in the Ugandan participants and our previous work showing an association between T regulatory cells, TGF- $\beta$, and collagen formation (40). We stained tissue sections from Group 1 and Group 2 with antibodies directed against FoxP3 and found no difference in the frequency or location of T regulatory cells. 
A

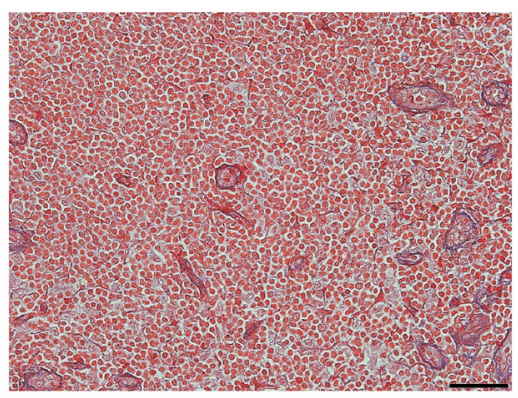

C

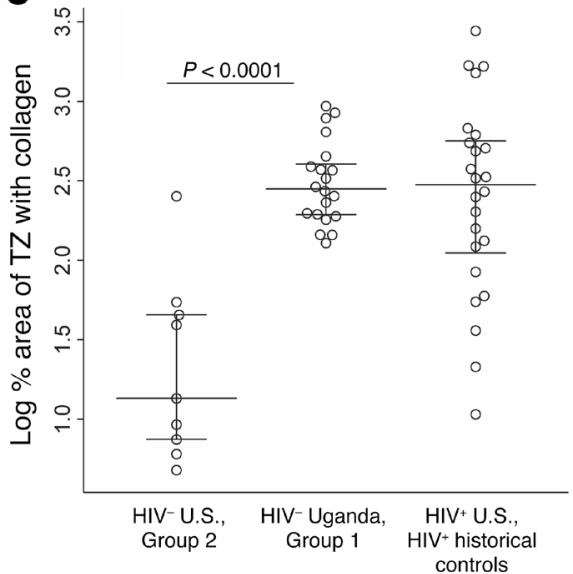

B

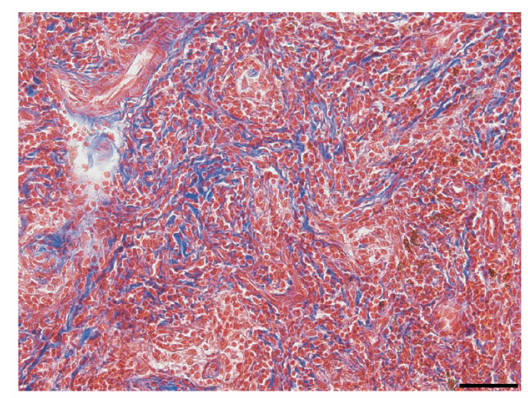

。

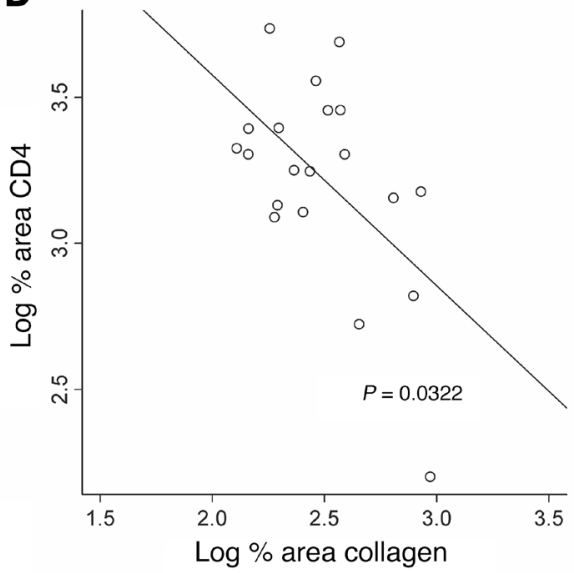

Figure 2. Increased T cell zone fibrosis in people from Uganda. A representative section of LNs stained with trichrome from a person from the U.S. (A) was compared with one from a person from Uganda (B). There was an increase in the amount of collagen (blue fibers) in the Ugandan sample. LN tissues from the Ugandan participants in Group 1 have a similar amount of collagen as $L N$ tissues from HIV- people from the U.S. in Group 2 (C). We see the expected inverse relationship between TZ collagen and the size of the resident $\mathrm{CD} 4^{+} \mathrm{T}$ cell population in the HIV- Ugandans (D). Scale bar indicates 50 $\mu \mathrm{m}$ and magnification is $\times 20$.
We next examined the FRCn of the TZ as it is an important structural element that we have previously shown to be damaged in $\mathrm{HIV}^{+}$people when collagen accumulates in the $\mathrm{TZ}$ (41). We stained tissues with an antibody against desmin and measured the area of the $\mathrm{TZ}$ that stained positive. In Figure 3A we show a representative section of the TZ of a LN from Group 2 in which the desmin-positive TZ area is 22.6\%; in Group 1 (Figure 3, B and C) the mean area of the desmin-positive TZ was 9.5\% (range $5.1 \%$ $19.4 \%)$. As expected, there was a direct and significant correlation between the log-transformed area of the TZ that was desmin positive and the log-transformed size of the $\mathrm{TZ} \mathrm{CD} 4^{+} \mathrm{T}$ cell population $(P<0.0001$, Figure 3D).

Other significant histological abnormalities in LNs from Ugandans. In addition to the abnormal fibrosis described above with loss of the FRCn, we also found a pathologic abnormality known as dermatopathic lymphadenopathy (42) in virtually all LN tissues from Ugandans. This condition, associated with skin malignancies and chronic skin abnormalities in Western populations, is characterized by decreased $\mathrm{CD} 4^{+} \mathrm{T}$ cells in an expanded TZ, with reduced numbers of primary and secondary B cell follicles (Figure 4, A and B). Other features include sinus histiocytosis, melanin in phagocytes, and compression of B cell follicles against the outer cortex from TZ expansion, leading to their involution. This pathology is sometimes misdiagnosed as Hodgkin's lymphoma or another hematologic malignancy, but it is usually a benign diagnosis unless associated with skin malignancy. None of the Ugandan participants had known skin diseases. We did not see any features of dermatopathic lymphadenopathy in LNs from the U.S. participants.

In summary, we found significant differences in the LN anatomy when we compared HIV- people from the U.S. with HIV' peo- ple from Uganda. All subjects in our Ugandan cohort had evidence of increased IA and fibrotic damage to the TZ. In addition, we

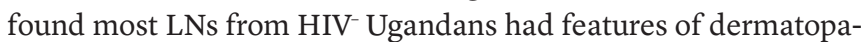
thic lymphadenitis, which would be considered abnormal in the U.S. We next performed a vaccination experiment to determine if these abnormalities were associated with immune dysfunction.

YFV antibody responses were blunted and of short duration. We enrolled 20 members of Group 1 into a follow-up study through which we obtained an inguinal LN biopsy and vaccinated participants with a standard dose of YFV in the contralateral thigh. We obtained another LN sample 10-14 days later from the inguinal region draining the thigh where the vaccine was given, as this is the time when GC formation should be evident $(37,38)$. LN tissues were analyzed to determine changes in the size of B cell populations, frequency and location of GCs, levels of IA in the TZ, and frequency and location of Tfh cells. Plasma was collected at weeks 2, 3, and 60 after YFV administration for monitoring of YFV antibody titers measured by plaque reduction assay (PRA). At baseline, there was an unexpected paucity of primary follicles with few secondary follicles (germinal centers). After vaccination, we found no increase in primary or secondary follicle formation and, while the comparison of increase in frequency of $\mathrm{Ki} 67^{+}$cells before and after YFV was significant ( $P=0.0008$, Figure 5A), most (69\%) had less than a $50 \%$ increase. At baseline, just prior to vaccination, the mean frequency of $\mathrm{Ki}^{+} 7^{+}$cells was 505 cells/gram LN (range 265-1,822 cells/gram LN) whereas 2 weeks after vaccination the mean frequency was 746 cells/gram LN (range 308-1,645 cells/ gram LN), a difference that was not statistically significant. We also measured changes in the size of the B cell population, expecting a significant increase after vaccination, and found no change. 

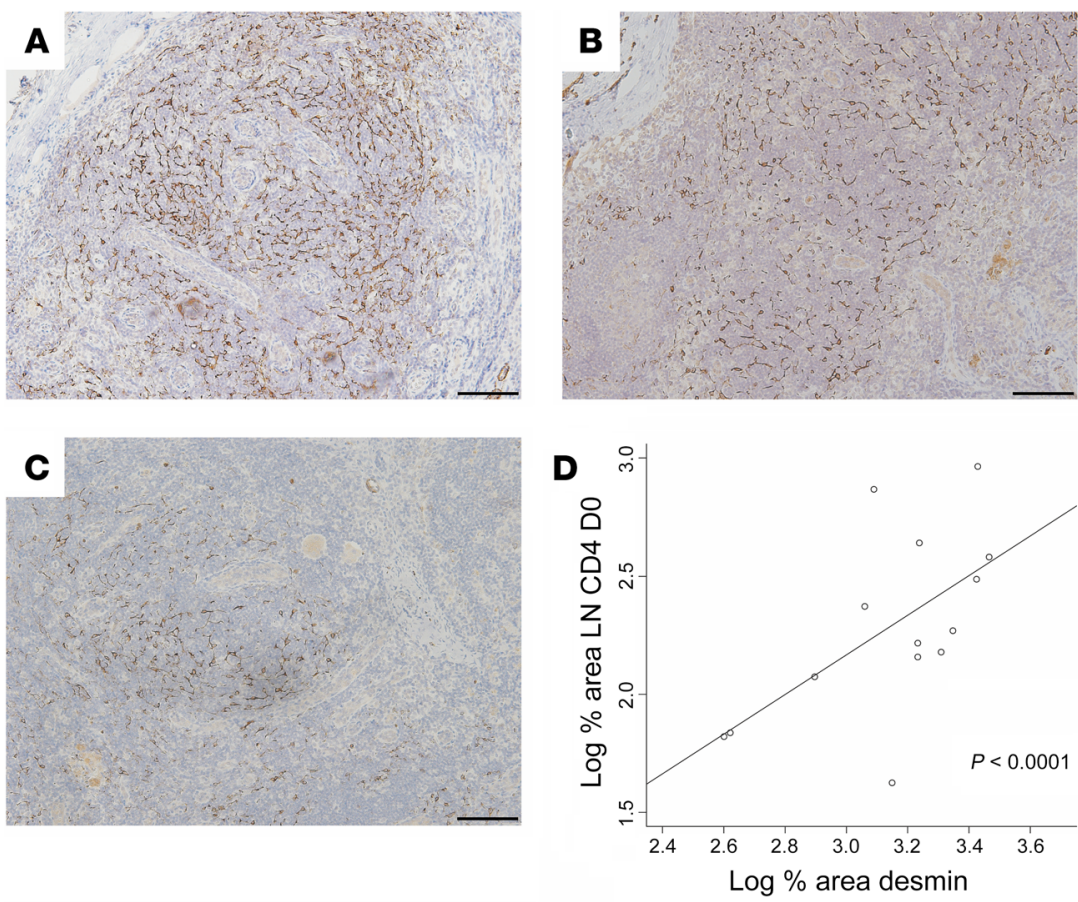

Figure 3. The fibroblastic reticular cell network (FRCn) is depleted in Ugandans. We used QIA to identify TZ desmin in HIV- people in the U.S. (Group 2, A) and people from Uganda (Group 1, B and $\mathbf{C}$ ) and then used quantitative image analysis to compare the amount of desmin in the section to the size of the CD4 ${ }^{+} T$ cell population in the LN (D), showing the significant and direct relationship. Scale bar indicates $100 \mu \mathrm{m}$ and magnification is $\times 20$.

ies). The starting dilution of the assay was 1:100 (Figure 6B). All plasma samples measured at the week-3 time point had detectable antibodies with a $1.3 \log$ range and there was a median decrease of $0.9 \log$ by week 60 . The peak titer and the decay characteristics are similar to those reported by Trautmann in a similar group of Ugandans (ref. 12 and our unpublished observations). Given the variable response in development of antibodies, the rapid decline, and the anatomic changes we found in LNs from Ugandan participants as well as the lack of immune response after vaccination, we looked for an anatomic correlate of poor vaccine response and found that measures of the FRCn correlated to the peak titer we measured 3 weeks after vaccination $(P=0.02$, Figure $6 C)$. Thus, the more damage to the FRCn the smaller the peak antibody titer.

Tfh cells are depleted in $\mathrm{HIV}^{-}$Ugandans and do not increase with $Y F V$. The fact that we did not see an increase in follicle formation or in B cell numbers in LNs suggested we assess the population of Tfh cells. Tfh cells are required for follicle formation and their number could well be depleted due to loss of the FRCn from inflammation-induced collagen formation (21, 27-29). We used a multiplexed confocal imaging assay allowing for the simultaneous detection of 6 markers to stain LN tissues from all 20 participants before

The mean area of the follicles with B cells prior to vaccination was $25.5 \%$ (range $15.69 \%-39.4 \%$ ) whereas after vaccination the mean area was $24.1 \%$ (range $14.0 \%-34.1 \%, P=0.34$ ) (Figure $5 B$ ). In 12 of 19 (63\%) participants there was no evidence for follicle formation as a response to vaccination.

Plasma samples were analyzed by PRA for titers of neutralizing antibodies to yellow fever. Initially we compared the week-2 samples between Group 1 and Group 3 using a PRA assay where the readout is reduction of the number of plaques in the presence of participant plasma. The starting dilution was 1:20 and we found only 5 people in Group 1 who had detectable antibodies, whereas all participants in Group 3 had detectable antibodies $(P<0.0001$, Figure 6A). We next studied the longitudinally collected plasma samples from Group 1 using an assay where the readout is cytopathic effect (CPE) of a Vero cell monolayer by YFV (CPE will not be observed in the presence of neutralizing plasma antibod- and after vaccination with antibodies directed against CD20, CD8, Ki67, PD1, and CD57 to assess the location and distribution of Tfh cells in these tissues. We used established markers (PD1, CD57) characterizing human Tfh $\mathrm{CD} 4^{+} \mathrm{T}$ cell populations (43-45). We show in Figure 7 representative images from before and after vaccination describing the 3 patterns observed. The striking finding is that relatively few participants (3 of 20) had well-developed GCs with PD1 ${ }^{\text {hi }}$ cells and CD57 ${ }^{+}$cells TFh cells (e.g., participant 1996, Figure 7, B and D). A total of 4 of 20 had some evidence of follicle reactivity but did not present a profile of a well-defined, polarized GC that contained PD1 ${ }^{\text {hi }}$ and CD57 ${ }^{+}$ cells (e.g., participant 1682, Figure 7, F and H). However, most (12 of 20) had few, if any, GCs and those that were present were nonreactive as evidenced by lack of Ki67 staining that typically reflects B lymphocyte activation and proliferation (e.g., participant 1688, Figure 7, J and L). We speculated that there might
Figure 4. Dermatopathic lymphadenopathy and CD4 ${ }^{+} \mathrm{T}$ cell depletion in HIV- Ugandans. H\&E staining (A) of Ugandan LNs reveals prominent features of dermatopathic lymphadenitis, including sinus histiocytosis in the TZ (black arrows) and melanin in phagocytes (red arrow). CD20 staining to identify $B$ cells (B, black arrow) shows an expanded TZ (red arrow) compressing B cell follicles (which are reduced in number) against the capsule. Scale bar indicates $200 \mu \mathrm{m}$ and magnification is $\times 4$.
A

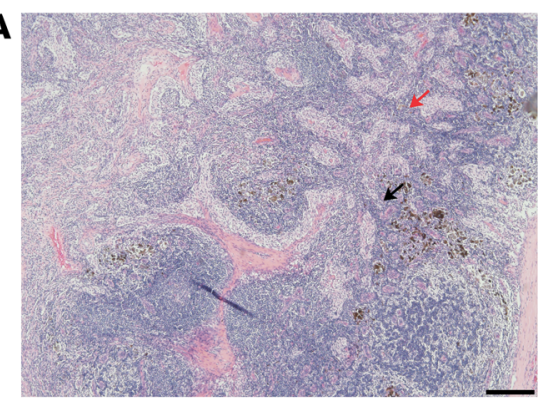

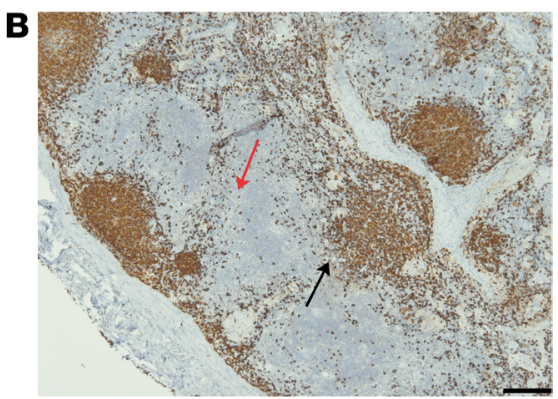



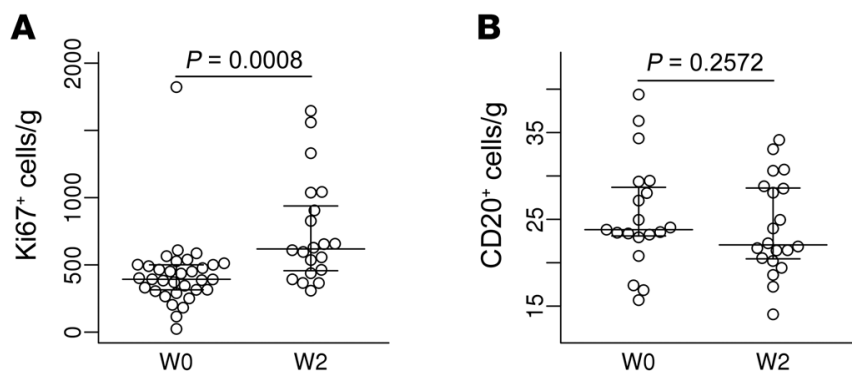

Figure 5. Ki67 and CD20 analysis in LNs before and $\mathbf{2}$ weeks after yellow fever vaccination in Group 1. There is no significant increase overall in the frequency of $\mathrm{Ki}^{\mathrm{i}} \mathrm{7}^{+}$or B cells in the LNs after vaccination.

be a proliferation of macrophages (MØ) in the B cell follicles that could cause disruption of the follicle and prevent normal function (as a consequence of IA). We stained tissue sections with antibodies directed against CD68 and found no evidence for increased numbers of $\mathrm{M} \varnothing$ in B cell follicles of Group 1 when compared with Group 2.

Ugandans exhibited a skewed cytokine response to YFV vaccination. We next performed an analysis of changes in plasma cytokines obtained before and 2 weeks after YFV in groups 1 and 3 in an attempt to discover possible signatures for the persistent inflammation and LN architecture damage. We measured IL-1 $\beta$, IL-4, IL-6, IL-10, IL-17A, IL-21, IL-22, IL-23, IL-13, MIP-1 $\beta$, TNF, CXCL13, IP-10, and TGF- $\beta$. As mentioned above, Ugandan participants had significantly higher levels of TGF- $\beta$ at baseline and also higher levels of the proinflammatory cytokine IL- 6 when compared with U.S. participants. There was no change in any of the analytes between the baseline and week 2 after vaccination for any of the U.S. participants other than IL-13 (46); however, we did measure significant changes in several cytokines in the Ugandan participants (Table 2). Following vaccination in the Ugandan group (Group 1) there was a significant increase in IL-10, IL-17A, IL-21, IL-22, IL-23, IL-1 $\beta$, CXCL13, and IP-10 (Figure 8 and Table 2). Levels of TGF- $\beta$ decreased significantly $(P=0.002)$ and there was a trend for a decrease in TNF levels
( $P=0.065$ for Ugandans). There was not a statistically significant change in MIP-1 $\beta$. The results of a lasso regression analysis show that IL- 6 and IL- $1 \beta$ at day 0 and IL-22, TGF- $\beta$, and IL- 6 at week 2 were predictive of yellow fever antibody titers at week 3. Only IL-1 $\beta$ was negatively correlated; the other predictive measures were positively correlated. We did not find any association among levels of cytokines either before or after vaccination and TZ fibrosis frequency of GC formation or Tfh cells. A possible explanation for this lack of correlation is that our cohort was small. A larger study may reveal some of these associations.

In summary, we have identified a process of inflammation and pathology in LT of HIV Ugandans that is associated with loss of the FRCn and $\mathrm{CD}^{+} \mathrm{T}$ cell depletion. While the pathologic changes are not as severe as we have described in HIV, they are significant nonetheless. Further, vaccination with a potent immunogen such as YFV does not result in a durable neutralizing antibody response, the magnitude of which is inversely correlated with the degree of FDCn loss. Finally, cytokine responses to vaccination are skewed to a pattern that suggests endemic infections may be an important limiting factor in the development of immune responses to a stimulus.

\section{Discussion}

A continuing challenge in the management of infectious diseases in the developing world is the ability to develop vaccines that promote effective and durable responses. As discussed above, there are several examples of vaccines that provide durable high levels of neutralizing antibody when used in the developed world but fail to do so when used in the developing world. These include rotavirus vaccine to control infectious diarrhea $(3,4,47$, 48); BCG vaccine for prevention of TB (1); and vaccines for cholera $(5,9)$; or polio $(6,8,10,11,49,50)$. Our data suggest that a potential mechanism for vaccine failures may be inflammatory damage to LN structures that are important for the development of humoral responses. We document in these otherwise healthy Ugandans significant architectural changes in the $\mathrm{TZ}$ and in the $\mathrm{B}$ cell follicles that are similar to what we have described in HIV
A

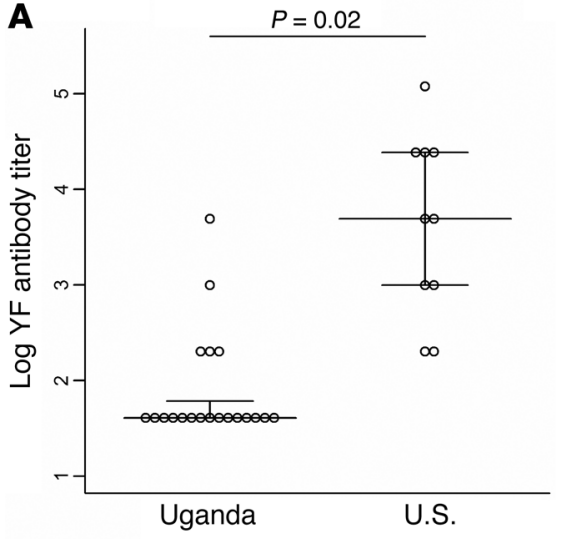

B

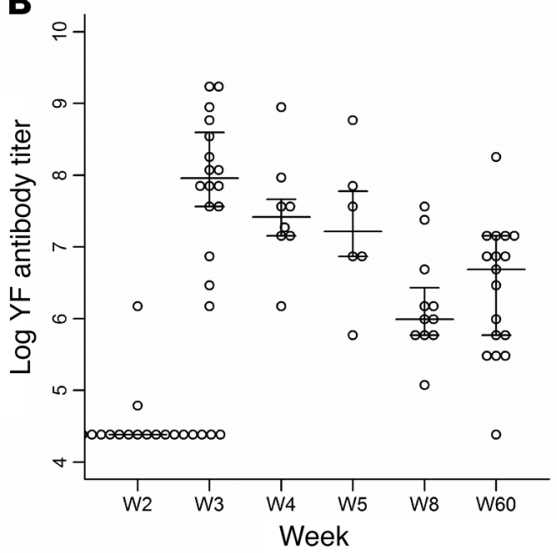

C

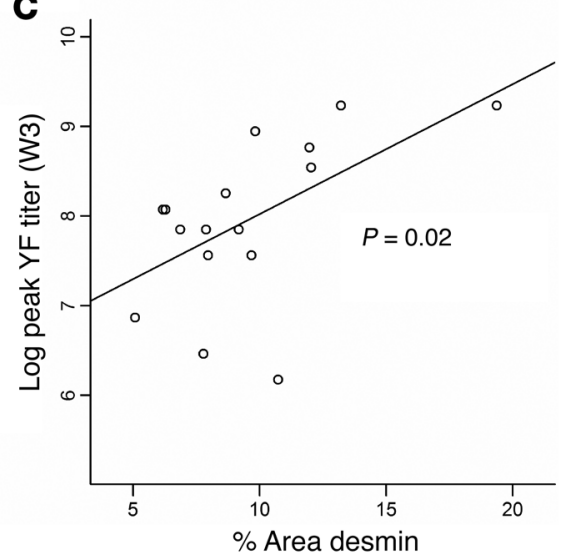

Figure 6. Yellow fever antibody titers. Titers of neutralizing antibody titers from the Ugandan and U.S. groups are compared using a plaque reduction neutralization assay with a starting dilution of 1:20 (A), demonstrating that by week 2 all of the U.S. participants had detectable antibodies but only 5 of 20 people from Uganda did. In (B) we show the peak titer of the Ugandan participants at day 21 (week 3) and the decline through month 14 . In (C) we show that measures of desmin in LNs correlate to peak antibody titer. 


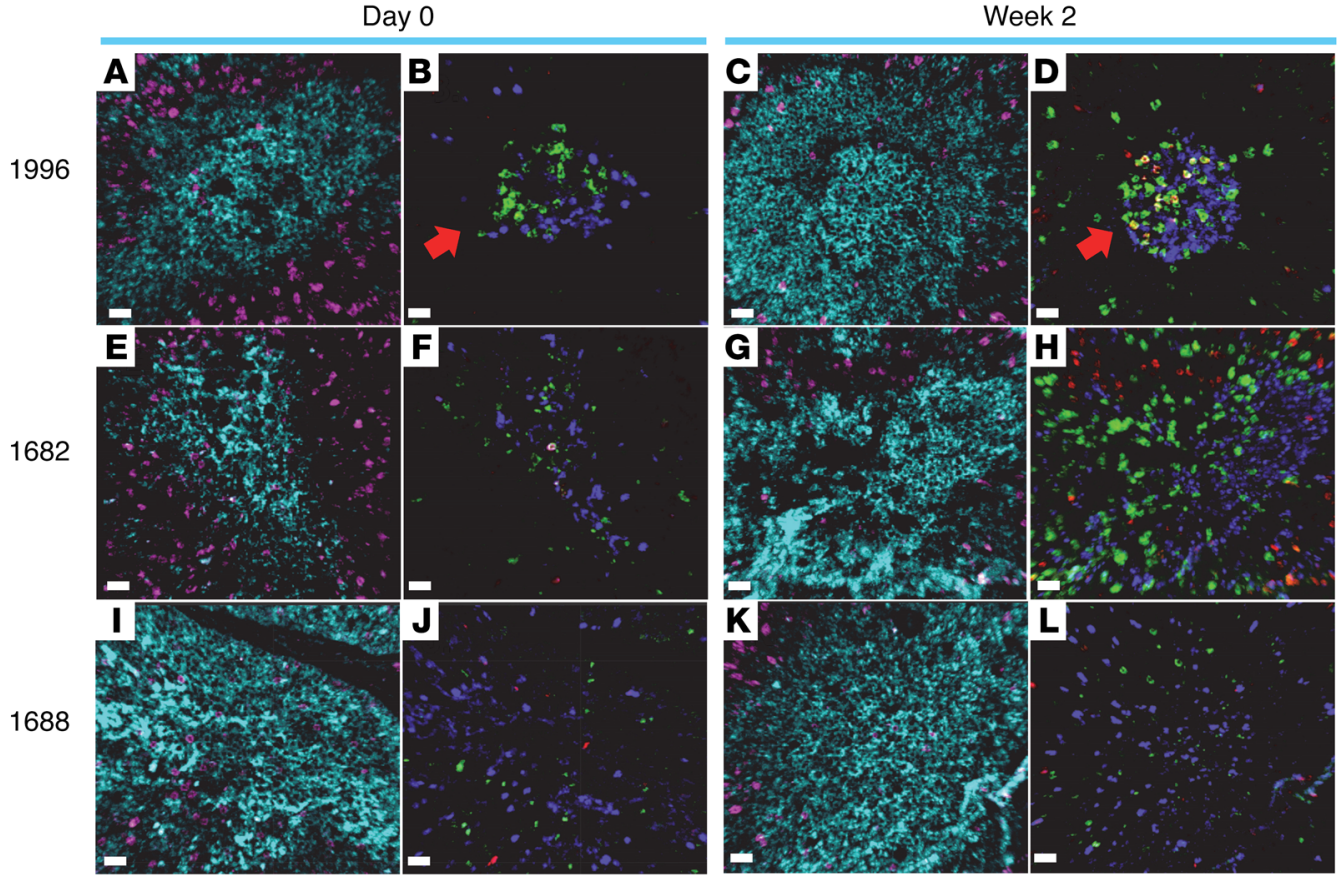

CD20 CD8 Ki67 PD1 CD57

Figure 7. B cell follicles are diminished and there is a paucity of $\mathbf{T}$ follicular helper cells in B cell follicles in Ugandans. This figure shows LN analysis from 3 different participants before vaccination and again at week 2 after vaccination. Participant 1996 has recognizable follicles before vaccination and formation of follicles after vaccination. The accumulation of PD1 staining cells within the secondary follicle (D) with green and blue staining cells in the secondary follicle (staining yellow) show an expected reaction to vaccination. Panel B shows participant 1682 with fewer, more poorly formed follicles at baseline and a lack of recognizable secondary follicles with vaccination. PD1 staining cells are not inside of the follicle structure. Participant 1688 has no recognizable follicles prior to vaccination and no response to vaccination. Scale bar indicates $20 \mu \mathrm{m}$

infection, albeit to a lesser extent, with collagen formation in the FRCn $(21,27,51)$. We compare in Figure 2C the amount of TZ collagen in HIV- Ugandans compared with $\mathrm{HIV}^{-}$and $\mathrm{HIV}^{+}$people in Minnesota, USA. It is worth noting that the median TZ collagen in $\mathrm{HIV}^{+}$Ugandans is even higher the mean of TZ collagen in HIV Ugandans. The mean area of the TZ with collagen was $12.4 \%$ (SD 3.4\%) in the HIV- Ugandan group but in HIV+ Ugandans the mean is $25.0 \%$ (SD 5.2\%) (our unpublished observations). In HIV infection, TZ fibrosis is caused by IA, which is brought on by replication of HIV in the tissues and recruitment of $\mathrm{T}$ regulatory cells to contain the replication (40). The specific cause of the increased IA and TZ fibrosis in the HIV- Ugandan group is unknown but is likely related to frequent endemic infections like malaria, TB, salmonella, and helminths. However, with these data we cannot exclude other factors that may contribute to TZ fibrosis and IA, such as genetics or environmental conditions unrelated to infection. The groups that we examined were racially and ethnically diverse; in Uganda all participants were East African and in Minnesota 2 of 12 participants were African American and the remaining were of European descent. We did find increased levels of proinflammatory and profibrotic cytokines at baseline, some of which are frequently associated with helminthic infections; however, the significant increase in IL-6, IL-10, and IL-17 could be more in line with an active bacterial infection. In addition, the elevated levels of TGF- $\beta$ and IL- 6 at baseline are consistent with prior exposures to extracellular pathogens that promote IL-17 responses. We believe the unusual plasma cytokine responses after YFV in Ugandan participants may arise in the context of an immune system that is skewed toward a response to pathogens the participants have recently experienced, and that this is the cause of IA-causing fibrosis and suboptimal antibody responses. It is tempting to speculate that this process is responsible for the significant variations in $\mathrm{CD} 4^{+}$ $\mathrm{T}$ cell numbers measured around the world; however, a definitive answer will likely require mechanistic studies in a mouse or other animal model in which factors such as genetics, food, and climate can be precisely controlled.

We did not find an association among circulating cytokines (including TGF- $\beta$ ), T regulatory cells, and TZ fibrosis. This may seem surprising as we have previously documented a mechanistic link between induction of T regulatory cells into the LNs as a response to HIV replication and TGF- $\beta$ production in response to HIV infection. TGF- $\beta$ directly caused induction of fibrosis in the $\mathrm{TZ}$ (40). In our previous experiments, we were able to study the process in acute infection of Rhesus macaques infected with SIV and obtain tissues and samples to analyze as the collagen was being formed. In the present study, it would be surprising to see an association because we measured collagen at 2 time points: close together, where we did not see any change, but also at a point where we would expect the process of collagen formation to be a chronic one. It is unlikely that levels of collagen would correlate with these other more dynamic factors. 

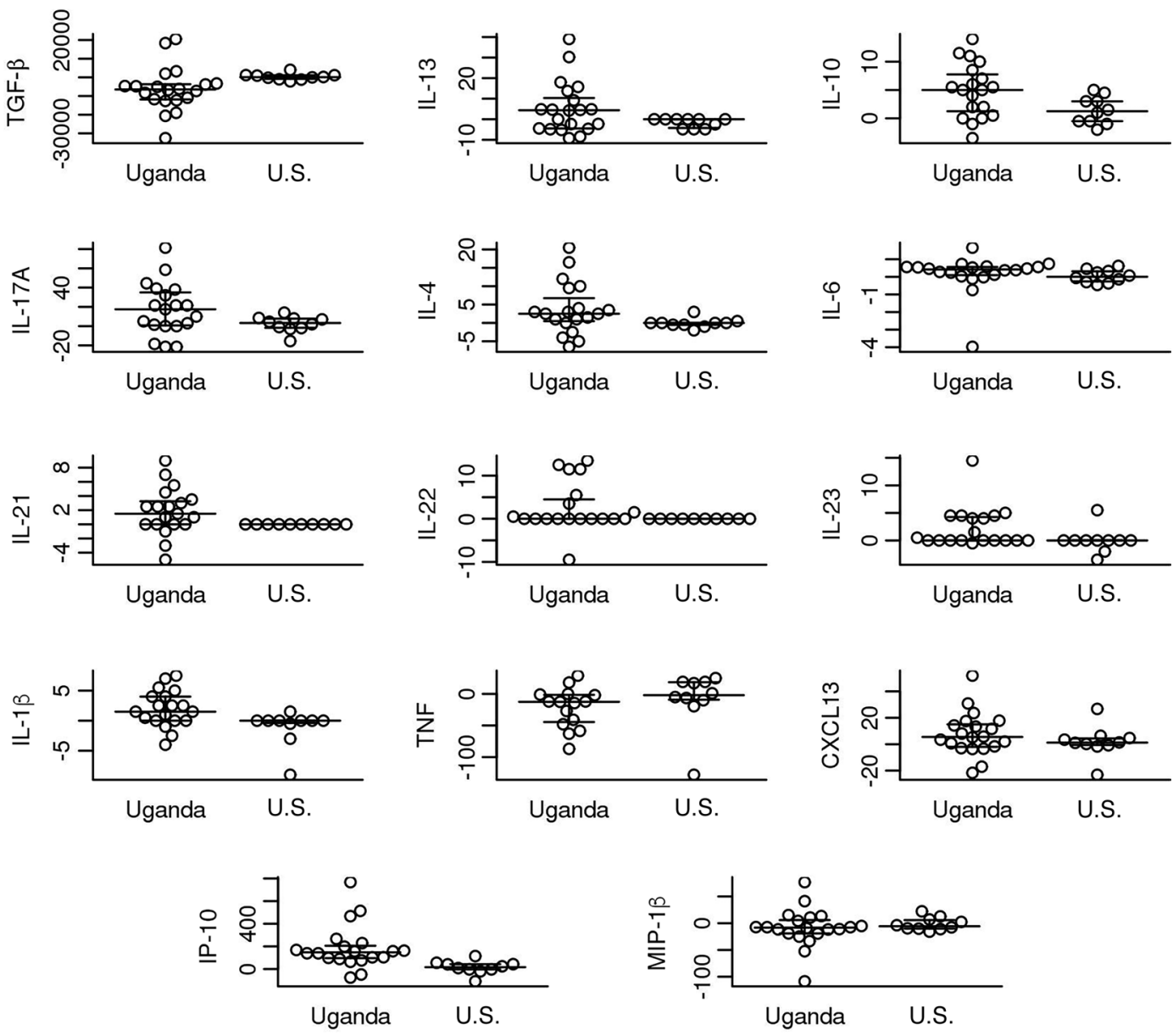

Figure 8. Changes to plasma cytokines with yellow fever vaccination in groups 1 and $\mathbf{3}$. Changes in measures of TCF- $\beta$ and CXCL13 are in pg/ml and all other cytokines are changes in mean fluorescence intensity (MFI). Mean plasma values and $P$ values for differences between groups and with yellow fever vaccine are shown in Table 2.

We chose YFV because it is very immunogenic, making it easy to detect associations between immune response to vaccination and the pathologic changes to lymph node structure that we have measured. The fact that YFV has demonstrated efficacy in the developing world where we would expect to see increased levels of TZ fibrosis is likely related to the fact that the vaccine also elicits a strong CD8 response (12). The fact that we and others (12) have demonstrated lower neutralizing antibody titers with a rapid rate of decay suggests a modulatory role for local environmental conditions, including endemic infections, in the generation of humoral responses to vaccines. Our data suggest a model where TZ fibrosis directly leads to decreases in T cells, including the Tfh cells, which limit B cell reactivity to antigens. We have shown in HIV infection that TZ fibrosis is a cause of T cell depletion due to loss of the FRCn and the subsequent loss of IL-7 which causes increased $\mathrm{T}$ cell apoptosis $(21,26-29)$. We think it likely that loss of the Tfh cells is due to this fibrotic process. What is unknown is if this process can be reversed with the antifibrotic therapy that cause the increased IA. We have previously shown that therapy with pirfenidone, a TGF- $\beta$ inhibitor, started in the earliest stages of infection with the SIV, can prevent accumulation of collagen in the $\mathrm{TZ}$ and limit loss of $\mathrm{T}$ cells (41). It is possible that limit- ing chronic exposure to these infections may provide the opportunity for lymphoid tissues to remodel and improve immune function. It would be interesting to study a cohort of individuals migrating from East Africa to the U.S. or Europe to determine if the $\mathrm{LN}$ architecture normalizes and vaccine responses improve. However, if abnormal LN architecture contributes to limiting vaccine efficacy, as our data suggest, modifying standard vaccine delivery approaches by altering dose, frequency, and type of adjuvant should be considered to enhance their efficacy and durability. This will be important if we are to address pathogens such as HIV, malaria, and TB, which are leading causes of morbidity and mortality in the developing world.

\section{Methods}

Subject recruitment and description. All subjects for Group 1 were recruited at the Joint Clinical Research Centre (JCRC) in Kampala, Uganda, and gave written informed consent that was approved by the IRBs of the University of Minnesota and the JCRC, and by the Uganda National Council of Science and Technology (UNCST). Protocols for the collection of samples were reviewed and approved by the IRBs of the University of Minnesota (Group 2) and Emory University (Group 3). All participants in each of the study groups gave written informed consent. 
Multiplex analysis of plasma cytokines before and after vaccination. Commercially available enzyme-linked immunosorbent assay was used according to the manufacturer's recommendation to measure plasma concentrations of total TGF- $\beta$ (Biolegend) and CXCL13 (R\&D Systems). Plasma levels of IL-1 $\beta$, IL-4, IL-6, IL-10, IL-13, IL-17A, IL-21, IL-22, IL-23, and TNF were determined by Bio-Plex magnetic bead-based multiplex assays according to the manufacturer's instructions (Bio-Rad Laboratories). Results were reported with mean fluorescence intensity.

Immunohistochemistry. Paraffin-embedded tissue sections $(5-\mu \mathrm{m}$ thick) mounted on glass slides were used for all staining protocols. Tissues were deparaffinized in xylene followed by graded ethanol and hydrated in deionized water. CD4 staining was performed using a mouse anti-CD4 monoclonal antibody (clone 1F6; Vector Laboratories) following heat-induced epitope retrieval in Tris-EDTA buffer (pH 9.0) at $125^{\circ} \mathrm{C}$ for 30 seconds. Ki67 staining was performed using a rabbit anti-Ki67 monoclonal antibody (clone SP6; ThermoFisher Scientific) following heat-induced epitope retrieval in Tris-EDTA buffer ( $\mathrm{pH}$ 9.0) at $125^{\circ} \mathrm{C}$ for 30 seconds. Both $\mathrm{CD} 4$ and Ki67 staining protocols included HRP-conjugated secondary antibodies and DAB visualization followed by counterstaining with hematoxylin. Collagen staining was performed using a modified Masson's trichrome staining protocol. CD68 staining (Biocare Medical) and FoxP3 (eBioscience) were done using standard protocols (40).

Quantitative image analysis (QIA). Images of all slides were obtained using an Aperio Scanscope CS. Ki67 staining was quantified using an algorithm written in Aperio ImageScope. CD4 and collagen stains were cropped, segmented, and quantified in Adobe Photoshop CS5 (Adobe Systems) using plug-ins from Reindeer Graphics as detailed previously $(26,27,51)$.

Confocal imaging analysis. Formalin fixed, paraffin-embedded tissue sections ( $5-\mu \mathrm{m}$ thick) were heated at $50^{\circ} \mathrm{C}$ for 1 hour, deparaffinized by immersing in sequential baths of xylene ( 2 minutes) and ethanol (8 minutes), and rehydrated in deionized water. Epitope retrieval was performed in a decloaking chamber (Biocare Medical) for 15 minutes at $110^{\circ} \mathrm{C}$, using the Borg Decloaker RTU solution (Biocare Medical). A hydrophobic barrier pen was applied to encircle the tissue section, and then sections were blocked with $1 \%$ BSA, $0.1 \mathrm{M}$ Tris, and $0.3 \%$ Triton $\mathrm{X}-100$ for 1 hour at room temperature (RT). Following this step, slides were stained with titrated amounts of nonconjugated antibody (CD8, IgG2b; clone 4B11) (Thermofisher Scientific) overnight at $4^{\circ} \mathrm{C}$. The next day, slides were rinsed 3 times in PBS for a total of 60 minutes and stained with appropriate Alexa Fluor-conjugated secondary antibody (goat anti-mouse IgG2b Alexa Fluor 546; ThermoFisher Scientific) for 2 hours at RT. Slides were then washed 3 times in PBS for a total of $60 \mathrm{~min}$ utes and stained for 2 hours at RT with titrated amounts of the following conjugated antibodies: PD1-Alx488 (catalog FAB7115G; R\&D Systems), CD20-efluor615 (clone L26; eBioscience), Ki67-Alx647 (clone B56; BD Biosciences), CD57-Alx680 (clone NK-1; in-house conjugated). After a final wash in PBS, slides were incubated with the nuclear stain JOJO-1 (Invitrogen) for 20 minutes, washed again in PBS, and mounted with Fluoromount G (SouthernBiotech). Image acquisition was performed on a Leica SP8 confocal microscope using either a $\times 20$ (NA 0.75) or a $\times 40$ (NA 1.30) objective with a $\times 1.5$ optical zoom at a $1,024 \times 1,024$ pixel density. Fluorophore spillover was corrected by imaging single-stained tissues and creating a compensation matrix via the Leica LAS-AF Channel Dye Separation module (Leica Microsystems). Postacquisition image analysis was carried out with Imaris software (version 8.2.1; BitPlane).
Yellow fever antibody neutralization assay. We used 2 different methods to test for the presence of neutralizing antibodies. In the first analysis we compared the week- 2 samples from groups 1 and 3 using a plaque reduction assay with methods that have been previously published (52). In the second method, used to test for the presence of neutralizing antibodies in samples collected longitudinally from Group 1, the readout was a reduction in cytopathic effect on Vero cells from YFV. Prior to testing, plasma samples were placed in a $56^{\circ} \mathrm{C}$ water bath for 30 minutes to inactivate complement. Plasma samples were then serially diluted in DMEM and incubated with 1,000 PFU YF-17D (NR-115; BEI Resources) in 96-well plates for 2 hours at $37^{\circ} \mathrm{C}$. Vero cells resuspended in complete DMEM (10\% FBS, $100 \mathrm{U} / \mathrm{ml}$ penicillin, $100 \mathrm{mg} / \mathrm{ml}$ streptomycin, and $2 \mathrm{mM}$ L-glutamine) were added at 5,000 cells/well. Monolayers were evaluated for cytopathic effect after a 7-day incubation at $37^{\circ} \mathrm{C}$. The first dilution at which monolayer destruction was observed was recorded as the endpoint titer. Samples were assayed in duplicate.

Statistics. Medians and quartiles were used to summarize continuous measures of baseline characteristics of participants. Tests for differences in molecular markers (e.g., Ki67) and cytokines were conducted using generalized estimating equations (GEEs) that controlled for sexual phenotype and age. These tests assumed an exchangeable correlation structure for cases in which data were available for more than 1 time point and included main effects and interactions for country and time (the analysis of Ki67 and CD2O did not include an interaction as this effect was not estimable due to the design). The results in Table 2 are GEE model-based estimates. All analyses were conducted using the statistical software R version 3.2.3 and the gee, xtable, and beeswarm packages were used. $P<.05$ was considered significant. Horizontal lines in the beeswarm plots indicate the median and the first and third quartiles.

Study approval. Human subject approval was obtained from the following IRB boards prior to the study: University of Minnesota, Minneapolis, Minnesota, USA; Joint Clinical Research Center, Kampala, Uganda; and the Uganda National Council of Science and Technology (UNCST), Kampala, Uganda. All participants in each of the study groups gave written informed consent.

\section{Author contributions}

CK, MR, P Mugyenyi, FS, BR, MML, DCD, and TWS designed the research study. KNM, RSA, JA, TES, SPC, J Schoephoerster, CP, $\mathrm{RL}$, and TMR conducted the experiments. KNM, MR, JGC, TH, GJB, FS, TES, SPC, P Muloma, PS, EM, MTA, DCD, and TWS acquired the data. CK, KNM, JGC, BG, RSA, JA, TR, J Schuster, CP, LZ, TMR, LT, RPS, RAK, RA, CR, DCD, and TWS analyzed the data. CK, KNM, RSA, BR, TMR, LT, RPS, MML, RAK, RA, CR, $\mathrm{DCD}$, and TWS wrote the manuscript.

\section{Acknowledgments}

We thank Ashley Haase (University of Minnesota) for his support and advice and Deborah Powell (University of Minnesota) for her encouragement and financial support to initiate this project. We also thank Deborah Masiira, G. Namayanja, J. Kabanda, H. Musana, Rose Byaruhanga, Milly Ndigendawani, Ezra Lutalo, Sofia Kasuswa, Charles Isabirye, Nicholas Karamagi, and Baonzi Necion for their advice and support (all from Joint Clinical Research Center in Kampala, Uganda). This work was supported in part by grants NIH AI074340, NIH UL1TR000114, NIH AIO93319, and NIH AIO36219, and by the intramural program of the National 
Institutes of Health. The views expressed herein are those of the authors and should not be construed to represent the positions of the U.S. Army or the Department of Defense.
Address correspondence to: Timothy W. Schacker, University of Minnesota, MMC 250, 516 Delaware Street, Minneapolis, Minnesota 55455, USA. Phone: 612.624.9955; Email: schacker@umn.edu.
1. Fine PE. Variation in protection by BCG: implications of and for heterologous immunity. Lancet. 1995;346(8986):1339-1345.

2. Patel M, Glass RI, Jiang B, Santosham M, Lopman B, Parashar U. A systematic review of anti-rotavirus serum IgA antibody titer as a potential correlate of rotavirus vaccine efficacy. JInfect Dis. 2013;208(2):284-294.

3. Hanlon $\mathrm{P}$, et al. Trial of an attenuated bovine rotavirus vaccine (RIT 4237) in Gambian infants. Lancet. 1987;1(8546):1342-1345.

4. Lanata CF, et al. Safety, immunogenicity, and protective efficacy of one and three doses of the tetravalent rhesus rotavirus vaccine in infants in Lima, Peru. J Infect Dis. 1996;174(2):268-275.

5. Hallander HO, et al. Calibrated serological techniques demonstrate significant different serum response rates to an oral killed cholera vaccine between Swedish and Nicaraguan children. Vaccine. 2002;21(1-2):138-145.

6. John TJ. Problems with oral poliovaccine in India. Indian Pediatr. 1972;9(5):252-256.

7. Fleming DT, et al. Herpes simplex virus type 2 in the United States, 1976 to 1994 . N Engl J Med. 1997;337(16):1105-1111.

8. John TJ, Christopher S. Oral polio vaccination of children in the tropics. III. Intercurrent enterovirus infections, vaccine virus take and antibody response. Am J Epidemiol. 1975;102(5):422-428.

9. Levine MM. Immunogenicity and efficacy of oral vaccines in developing countries: lessons from a live cholera vaccine. BMC Biol. 2010;8:129.

10. Patriarca PA, Wright PF, John TJ. Factors affecting the immunogenicity of oral poliovirus vaccine in developing countries: review. Rev Infect Dis. 1991;13(5):926-939.

11. Paul Y. Why polio has not been eradicated in India despite many remedial interventions? Vaccine. 2009;27(28):3700-3703.

12. Muyanja E, et al. Immune activation alters cellular and humoral responses to yellow fever 17D vaccine. J Clin Invest. 2014;124(7):3147-3158.

13. Buechler MB, Newman LP, Chohan BH, Njoroge A, Wamalwa D, Farquhar C. T cell anergy and activation are associated with suboptimal humoral responses to measles revaccination in HIV-infected children on anti-retroviral therapy in Nairobi, Kenya. Clin Exp Immunol. 2015;181(3):451-456.

14. Stelekati E, Wherry EJ. Chronic bystander infections and immunity to unrelated antigens. Cell Host Microbe. 2012;12(4):458-469.

15. Elias D, Wolday D, Akuffo H, Petros B, Bronner $\mathrm{U}$, Britton S. Effect of deworming on human $\mathrm{T}$ cell responses to mycobacterial antigens in helminth-exposed individuals before and after bacille Calmette-Guérin (BCG) vaccination. Clin Exp Immunol. 2001;123(2):219-225.

16. Cooper PJ, et al. Human infection with ascaris lumbricoides is associated with suppression of the interleukin-2 response to recombinant cholera toxin B subunit following vaccination with the live oral cholera vaccine CVD 103-HgR. Infect
Immun. 2001;69(3):1574-1580.

17. Sabin EA, Araujo MI, Carvalho EM, Pearce EJ. Impairment of tetanus toxoid-specific Th1-like immune responses in humans infected with Schistosoma mansoni. J Infect Dis. 1996;173(1):269-272.

18. Hunt PW. HIV and inflammation: mechanisms and consequences. Curr HIV/AIDS Rep. 2012;9(2):139-147.

19. Hunt PW, et al. Relationship between T cell activation and CD4+ T cell count in HIV-seropositive individuals with undetectable plasma HIV RNA levels in the absence of therapy. J Infect Dis. 2008;197(1):126-133.

20. Hunt PW, et al. T cell activation is associated with lower CD4+ T cell gains in human immunodeficiency virus-infected patients with sustained viral suppression during antiretroviral therapy. J Infect Dis. 2003;187(10):1534-1543.

21. Schacker TW, et al. Collagen deposition in HIV-1 infected lymphatic tissues and T cell homeostasis. J Clin Invest. 2002;110 (8):1133-1139.

22. Gretz JE, Kaldjian EP, Anderson AO, Shaw S. Sophisticated strategies for information encounter in the lymph node: the reticular network as a conduit of soluble information and a highway for cell traffic. J Immunol. 1996;157(2):495-499.

23. Kaldjian EP, Gretz JE, Anderson AO, Shi Y, Shaw S. Spatial and molecular organization of lymph node $T$ cell cortex: a labyrinthine cavity bounded by an epithelium-like monolayer of fibroblastic reticular cells anchored to basement membrane-like extracellular matrix. Int Immunol. 2001;13(10):1243-1253.

24. Gretz JE, Anderson AO, Shaw S. Cords, channels, corridors and conduits: critical architectural elements facilitating cell interactions in the lymph node cortex. Immunol Rev. 1997;156:11-24.

25. Gretz JE, Norbury CC, Anderson AO, Proudfoot AE, Shaw S. Lymph-borne chemokines and other low molecular weight molecules reach high endothelial venules via specialized conduits while a functional barrier limits access to the lymphocyte microenvironments in lymph node cortex. JExp Med. 2000;192(10):1425-1440.

26. Estes J, et al. Collagen deposition limits immune reconstitution in the gut. J Infect Dis. 2008;198(4):456-464.

27. Schacker TW, et al. Lymphatic tissue fibrosis is associated with reduced numbers of naive CD4+ T cells in human immunodeficiency virus type 1 infection. Clin Vaccine Immunol. 2006;13(5):556-560.

28. Zeng M, et al. Cumulative mechanisms of lymphoid tissue fibrosis and T cell depletion in HIV-1 and SIV infections. JClin Invest. 2011;121(3):998-1008.

29. Zeng M, et al. Lymphoid tissue damage in HIV-1 infection depletes naïve T cells and limits T cell reconstitution after antiretroviral therapy. PLOS Pathog. 2012;8(1):e1002437.

30. Lugada ES, et al. Population-based hematologic and immunologic reference values for a healthy Ugandan population. Clin Diagn Lab Immunol. 2004;11(1):29-34
31. Messele T, et al. Reduced naive and increased activated CD 4 and CD8 cells in healthy adult Ethiopians compared with their Dutch counterparts. Clin Exp Immunol. 1999;115(3):443-450.

32. Malaza A, Mossong J, Bärnighausen T, Viljoen J, Newell ML. Population-based CD4 counts in a rural area in South Africa with high HIV prevalence and high antiretroviral treatment coverage. PLOS ONE. 2013;8(7):e70126.

33. Tsegaye A, et al. Immunohematological reference ranges for adult Ethiopians. Clin Diagn Lab Immunol. 1999;6(3):410-414.

34. Valiathan R, Deeb K, Diamante M, Ashman M, Sachdeva N, Asthana D. Reference ranges of lymphocyte subsets in healthy adults and adolescents with special mention of T cell maturation subsets in adults of South Florida. Immunobiology. 2014;219(7):487-496.

35. Fletcher AL, et al. Lymph node fibroblastic reticular cells directly present peripheral tissue antigen under steady-state and inflammatory conditions. J Exp Med. 2010;207(4):689-697.

36. Cremasco V, et al. B cell homeostasis and follicle confines are governed by fibroblastic reticular cells. Nat Immunol. 2014;15(10):973-981.

37. Kelsoe G. The germinal center: a crucible for lymphocyte selection. Semin Immunol. 1996;8(3):179-184.

38. Allen CD, Okada T, Cyster JG. Germinal-center organization and cellular dynamics. Immunity. 2007;27(2):190-202.

39. Akondy RS, et al. The yellow fever virus vaccine induces a broad and polyfunctional human memory CD8+ T cell response. J Immunol. 2009;183(12):7919-7930.

40. Estes JD, et al. Premature induction of an immunosuppressive regulatory $\mathrm{T}$ cell response during acute simian immunodeficiency virus infection. JInfect Dis. 2006;193(5):703-712.

41. Estes JD, et al. Antifibrotic therapy in simian immunodeficiency virus infection preserves CD4+ T-cell populations and improves immune reconstitution with antiretroviral therapy. J Infect Dis. 2015;211(5):744-754.

42. Cooper RA, Dawson PJ, Rambo ON. Dermatopathic lymphadenopathy a clinicopathologic analysis of lymph node biopsy over a fifteen-year period. CalifMed.1967;106(3):170-175.

43. Crotty S. Follicular helper CD4 T cells (TFH). Annu Rev Immunol. 2011;29:621-663.

44. Kim CH, Lim HW, Kim JR, Rott L, Hillsamer P, Butcher EC. Unique gene expression program of human germinal center T helper cells. Blood. 2004;104(7):1952-1960.

45. Kim JR, Lim HW, Kang SG, Hillsamer P, Kim CH. Human CD57+ germinal center-T cells are the major helpers for GC-B cells and induce class switch recombination. BMC Immunol. 2005;6:3.

46. Querec TD, et al. Systems biology approach predicts immunogenicity of the yellow fever vaccine in humans. Nat Immunol. 2009;10(1):116-125.

47. Linhares AC, et al. Immunogenicity, safety and efficacy of tetravalent rhesus-human, reassortant 
rotavirus vaccine in Belém, Brazil. Bull World Health Organ. 1996;74(5):491-500.

48. Mirzayeva R, Steele AD, Parashar UD, Zaman K, Neuzil KM, Nelson EA. Evaluation of rotavirus vaccines in Asia--are there lessons to be learnt? Vaccine. 2009;27 Suppl 5:F120-F129.

49. John TJ. Antibody response of infants in tropics to five doses of oral polio vaccine. $\mathrm{Br}$ Med J. 1976;1(6013):812.

50. John TJ, Jayabal P. Oral polio vaccination of children in the tropics. I. The poor seroconversion rates and the absence of viral interference. $A m J$ Epidemiol.1972;96(4):263-269.

51. Schacker TW, et al. Amount of lymphatic tissue fibrosis in HIV infection predicts magnitude of HAART-associated change in peripheral CD4 cell count. AIDS. 2005;19(18):2169-2171.

52. Calisher $\mathrm{CH}$, et al. Antigenic relationships between flaviviruses as determined by cross-neutralization tests with polyclonal antisera. J Gen Virol. 1989;70(Pt 1):37-43. 